\title{
A Neonatal Nurse Training Program in Kangaroo Mother Care (KMC) Decreases Barriers to KMC Utilization in the NICU
}

\author{
Karen D. Hendricks-Munoz, MD, MPH ${ }^{1}$ Roslyn M. Mayers, BSN, CCRN² \\ ${ }^{1}$ Division of Neonatal Medicine, Virginia Commonwealth University \\ School of Medicine, Children's Hospital of Richmond at VCU, \\ Richmond, Virginia \\ 2 Neonatal Intensive Care Unit, Bellevue Hospital Center, New York, \\ Address for correspondence Karen D. Hendricks-Munoz, MD, MPH, \\ Children's Hospital of Richmond at VCU, 1001 East Marshall Street-VCU \\ Health System, Critical Care Hospital, NICU-6, P.O. Box 980276, \\ Richmond, VA 23298 (e-mail: khendricks-munoz@mcvh-vcu.edu).
} New York

Am J Perinatol 2014;31:987-992.

\begin{abstract}
Keywords

- neonatal nurse

- kangaroo mother care

- neonatal intensive care unit

- simulation training

Objective This study assessed the impact of a nurse simulation training program on perception of kangaroo mother care (KMC) value and transfer skill competency.

Study Design An 8-item Likert scale skill survey tool and a 24-item Likert developmental care survey tool were used in a prospective cohort study to analyze perceptions of 30 neonatal nurses who underwent a comprehensive KMC simulation-based training program. Competency skills were evaluated pretraining and tracked by direct observation for 6 months posttraining. Pre- and postsurvey data were analyzed and KMC utilization for preterm infants born at $\leq 34$ weeks' gestation was determined.

Results Nurses' competency in infant transfer improved, especially in infants receiving nasal continuous positive airway pressure or ventilator support, from 30 to $93 \%$ or 10 to $50 \%$, respectively, $p<0.0001$. Neonatal nurses' perceived KMC value increased from 50 to $100 \%, p<0.001$, and parent KMC utilization increased from 26.5 to $85.9 \%$, $p<0.0001$. Nurses' support for parental visitation improved from 38 to $73 \%$, $p<0.001$; discussion of KMC with parents on the 1st day increased from 5 to $45 \%$, $p<0.001$; and initial day of KMC provision improved from $18.0 \pm 2.7$ to $5.6 \pm 1.2$ days, $p<0.001$.

Conclusions A comprehensive simulation-based KMC education program improved nurses' perception of KMC value, their competency and comfort in infant transfer for KMC care, and successfully promoted KMC parent utilization for the preterm infant in the neonatal intensive care unit.
\end{abstract}

\section{Background}

Kangaroo mother care (KMC), a specific method of care in which the mother is supported to hold her naked diaper-clad infant skin to skin upright between her breasts, provides health benefits for infant and mother. ${ }^{1-5}$ These include diminishing infant stress or pain and enhancing cardiorespiratory and intestinal physiology as well as enhancing mater-

received

October 10, 2013

accepted after revision

December 26, 2013

published online

March 28, 2014 nal lactation, diminishing risk of postpartum blues, and enhancing parenting confidence and self-esteem. ${ }^{1-6} \mathrm{KMC}$ is considered an important component of developmental care and family-centered care in the neonatal intensive care unit (NICU), to further support the role of the mother and father and members of the care team with the medical caregivers. ${ }^{7,8}$ Indeed, KMC provided by fathers has been associated with improved confidence in paternal role. ${ }^{9,10}$ Despite the
Copyright $\odot 2014$ by Thieme Medical Publishers, Inc., 333 Seventh Avenue, New York, NY 10001, USA. Tel: +1(212) 584-4662.
DOI http://dx.doi.org/ 10.1055/s-0034-1371359. ISSN 0735-1631. 
well-known benefits, barriers to provision of this care remain, notably related to provider perception of value, NICU culture, and perceived difficulty in provision of KMC for the preterm infant. ${ }^{11-14}$ As parent educators for provision of KMC, the neonatal nurse is a vital advocate in the utilization of KMC in the NICU, and guides the NICU team and the parents in the perception of infant KMC readiness, the determination that the infant is medically stable for KMC, as well as overall value of this care. The neonatal nurse must have a level of understanding of the benefits of KMC as well as comfort and skill to safely transfer infants who are provided this level of care. Previous evaluation of barriers to the use of KMC in the NICU indicated neonatal nurse's comfort level with infant transfer out of incubator to the KMC position on the parent's chest especially in those infants receiving respiratory support. ${ }^{12-14}$ We hypothesized that competency with transfer of the preterm infant receiving respiratory support impacted on the nurse's perceived KMC value and decreased provision of KMC in the NICU. The aim of this study was to determine neonatal nurses' perception of comfort, skill, and ability to provide safe KMC transfers and the impact of a structured competencybased KMC education training program that includes transfer simulation on nurses' perception, competency, and subsequent parent utilization of KMC.

\section{Methods}

This was a prospective cohort study of neonatal nurses at Bellevue Hospital Center in New York City. This study used two quantitative surveys for pre- and post-KMC education training for the 32 participating nurses. The five-point Likert rating scale for the questions included 1 (strongly agree) to 5 (strongly disagree). All inborn infants $\leq 34$ weeks' gestation admitted to the Bellevue NICU during the study period were eligible and prospectively assessed for parent utilization of KMC. The KMC nursing educational curriculum designed was provided in three workshops during December 5, 2008, to January 5, 2009. The workshops consisted of 7.5 hours of didactic education that included presentations by the medical staff on the following: the scientific basis of KMC, the impact of KMC on breastfeeding, supporting families during KMC, assessing and identifying infants, as well as parent and staff readiness for KMC. A manikin simulation practicum included medical scenarios where nurses accepted roles as parents (role play) to assess nurses' provision of parental KMC education as well as identify skill level in the evaluation of infants, parents, and staff's readiness for KMC. Each nurse completed five KMC practicum stations with infant mannequins receiving (1) room air, (2) nasal cannula, (3) nasal continuous positive airway pressure (NCPAP), (4) synchronized inspiratory positive airway pressure (SIPAP), and (5) intubation on conventional ventilators. Debriefings were held immediately following each scenario. High fidelity mannequins controlled by a biomedical engineering technician included transfers with simulation of apnea and bradycardia episodes. The training incorporated a KMC nursing competency skills checklist. Post-KMC training survey of registered nurses' (RNs) comfort and knowledge levels was performed after training and collected, analyzed, and compared with pre-KMC training survey data. Nurses who were undergoing competency/skills training were under direct observation in the NICU by senior staff every day for 6 months posttraining. Parent participation of infant KMC exposure was collected through the electronic medical records for infants born 6 months before and 18 months after the training, June 1, 2008, to May 31, 2010. Institutional review board approval was obtained to conduct this study. Statistical analysis was conducted using SPSS version 17 for Windows (Chicago, IL). Fisher exact test, Pearson chi-square test, and independent samples $t$-test were used for statistical analyses of categorical independent and continuous variables.

\section{Results}

\section{Competency of Nurses in the Provision of KMC Pretraining}

A total of 30 nurses participated in the study. The demographic characteristics of the nurses are detailed in - Table 1 . The pre-KMC training survey data identified that $16.7 \%$ of RNs were uncomfortable and unable to perform KMC for stable infants in room air and that their level of comfort and competency worsened with the infants' increased respiratory care demands such as nasal cannula, NCPAP, and mechanical ventilation. Sixty-six percent were not comfortable in performing KMC with NCPAP and 90\% were not comfortable with the ventilated infant exposed to this therapy. Additionally, $90 \%$ felt uncomfortable in assisting their colleagues with the transfer of infants for KMC (-Fig. 1).

Table 1 Demographic characteristics of neonatal nurses

\begin{tabular}{|c|c|}
\hline Characteristics & NICU nurses, $N=30$ \\
\hline \multicolumn{2}{|l|}{ Race/ethnicity: N (\%) } \\
\hline Non-Hispanic white & $4(13.3)$ \\
\hline Hispanic & $1(3)$ \\
\hline Asian & $21(70)$ \\
\hline Non-Hispanic black & $2(6.7)$ \\
\hline Other & $2(6.7)$ \\
\hline \multicolumn{2}{|l|}{ Gender: N (\%) } \\
\hline Male & $2(7)$ \\
\hline Female & $28(93)$ \\
\hline \multicolumn{2}{|l|}{ Place of birth } \\
\hline U.S. born: N (\%) & $5(17)$ \\
\hline Non-U.S. born: N (\%) & $25(83)$ \\
\hline Age: Mean \pm SD & $46.9 \pm 9.7$ \\
\hline $\begin{array}{l}\text { Years living in United } \\
\text { States: mean } \pm \text { SD }\end{array}$ & $18.5 \pm 7.7$ \\
\hline $\begin{array}{l}\text { Years of work } \\
\text { experience: mean } \pm \text { SD }\end{array}$ & $20.6 \pm 9.5$ \\
\hline
\end{tabular}

Abbreviations: NICU, neonatal intensive care unit; SD, standard deviation. 


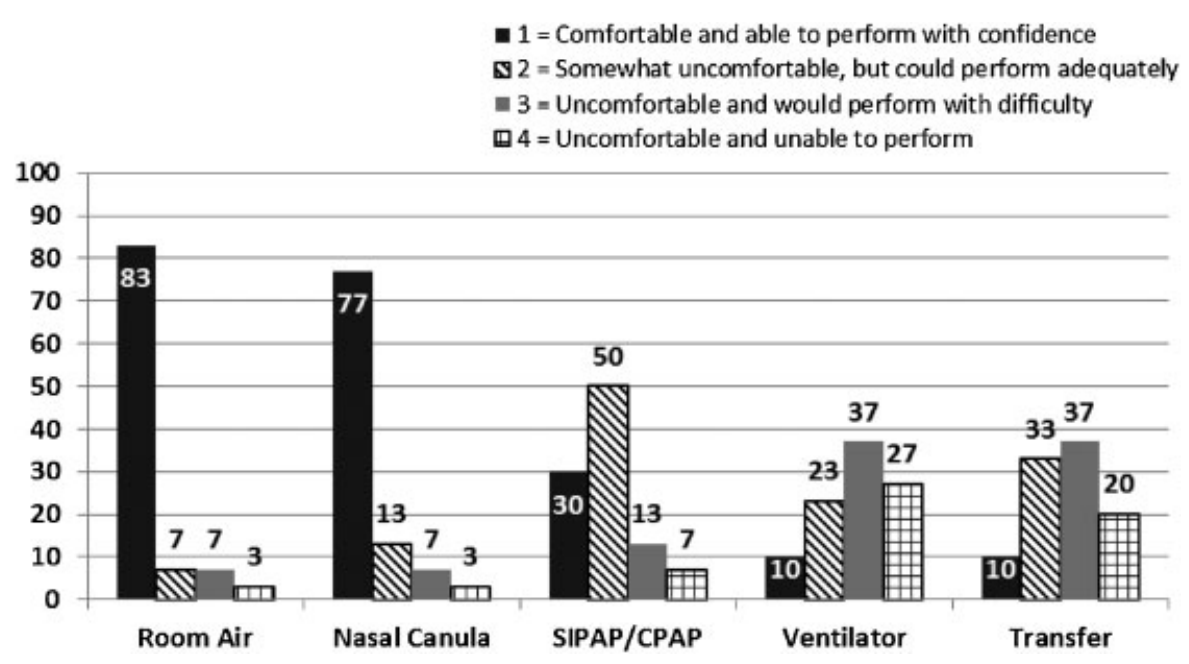

Fig. 1 Nurse's comfort level pretraining in the provision of kangaroo mother care.

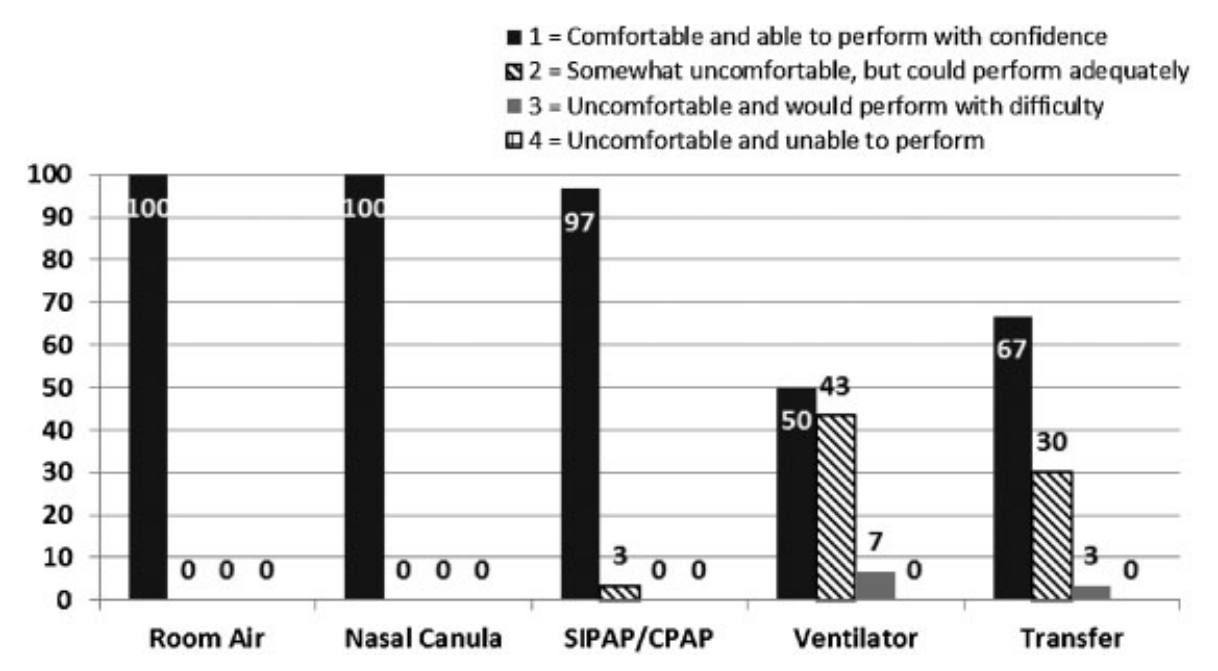

Fig. 2 Nurse's comfort level posttraining in the provision of kangaroo mother care.

\section{Competency of Nurses in KMC Provision Post-KMC Training}

Post-KMC training, comfort and competency of nurses in the provision of KMC for infants requiring NCPAP or mechanical ventilation improved significantly from 30 to $92 \%$ $(p<0.0001)$ and 10 to $48 \% \quad(p<0.004)$, respectively (-Fig. 2). Additionally, those who felt uncomfortable in this competency decreased to $0 \%$, which was significant for nasal cannula, NCPAP, and ventilator categories (-Table 2). This educational program improved the perception of value of KMC, the nurses' role in implementing KMC, as well as increased the nurses' value to encourage parent visitation in the NICU (-Fig. 3).

\section{Impact of KMC Training on Parent Utilization of KMC for Their Infant}

During the study period, 112 infants $<34$ weeks' gestation were eligible for KMC, 34 before training and 78 after the training period. There were no differences in the infant demographics during the evaluation period (-Table 3 ). The number of infants who received KMC increased from $26.5 \%$ in 2008 pretraining period to $85.9 \%$ in the posttraining period $(p<0001)$. KMC was provided primarily by the mother, although fathers who were interested in participating also provided KMC. The average infant initial KMC occurred at mean of $18 \pm 2.7$ days before training compared with $5.6 \pm 1.2$ days in the posttraining period. The mean duration of KMC pre-KMC training was $73.9 \pm 7.2$ minutes compared with $203.6 \pm 35.3$ minutes post-KMC training $(p<0.0006)$. There was no difference in the length of hospitalization, rate of mortality, or other morbidities such as risk of chronic lung disease or necrotizing enterocolitis.

\section{Discussion}

KMC is an important component of care that benefits the preterm infant in the NICU, mother, and family. ${ }^{1-7}$ Despite its known health and infant comfort benefits, barriers to implementation exist. ${ }^{11,13,15}$ In our NICU, past evaluations indicated that perception of value and comfort with implementation 
990 Nurse Training Program Decreases Barriers for KMC Use Hendricks-Munoz, Mayers

Table 2 Comparison of nurse competence pre- and posttraining response selection of no. 1 "Comfortable with procedure and perform with confidence"

\begin{tabular}{|l|l|l|l|}
\hline & Pretraining $(\boldsymbol{N}=30)$ & Posttraining $(\boldsymbol{N}=\mathbf{3 0})$ & Significance $(\boldsymbol{p}<\mathbf{0 . 0 5})$ \\
\hline Room air & $25(83 \%)$ & $30(100 \%)$ & NS \\
\hline Nasal canula & $23(76.6 \%)$ & $30(100 \%)$ & 0.0158 \\
\hline SIPAP/CPAP & $9(30.0 \%)$ & $28(93 \%)$ & 0.0001 \\
\hline Intubated & $3(10 \%)$ & $15(50 \%)$ & 0.0001 \\
\hline Transfer & $3(10 \%)$ & $20(66.6 \%)$ & 0.0001 \\
\hline
\end{tabular}

Abbreviations: CPAP, continuous positive airway pressure; NS, nonsignificant; SIPAP, synchronized inspiratory positive airway pressure. Note: Independent samples t-test and one-way ANOVA were used for statistical analyses.

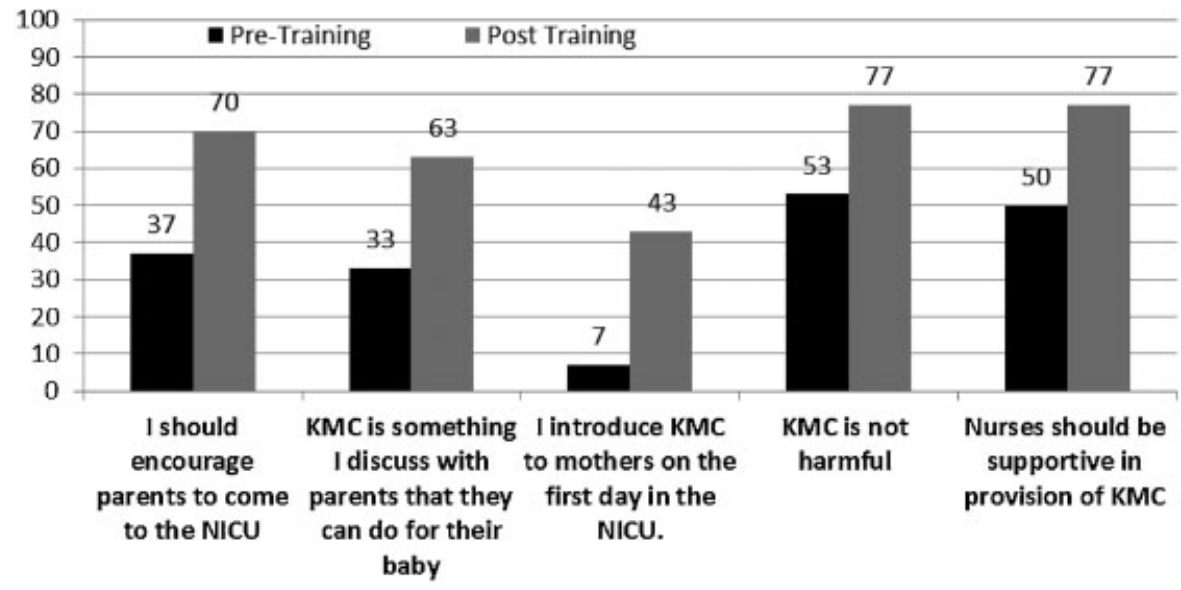

Fig. 3 Pre- and posttraining comparison of nurse's perception of value of family-centered care and kangaroo mother care.

of KMC interfered with utilization and promotion of KMC to parents. As no standardized educational program exists to address the competency needs of the neonatal nurse in understanding the scientific basis of KMC, methods of parent education, or competency in the KMC transfer and care for the preterm infant, we developed a comprehensive program to address this need. This investigation demonstrates that improving education and competency of nurse in KMC improved nurses' perceived value and decreased nurse barriers to KMC utilization that translated to increased use of KMC in eligible infants. The structured KMC education significantly improved NICU nurses' comfort level and their ability to provide KMC

Table 3 Inborn infants $\leq 34$ weeks who were provided KMC during the pre- and posttraining study period $(N=112)$

\begin{tabular}{|l|l|l|}
\hline Infant characteristics & Pretraining $(N=34)$ & Posttraining $(N=78)$ \\
\hline Gestational age, wk $( \pm$ SD) & $31.4 \pm 0.4$ & $30.7 \pm 0.3$ \\
\hline Birth weight, g ( \pm SD) & $1,771 \pm 85.9$ & $1,713 \pm 82.0$ \\
\hline Female (\%) & $15(44.1)$ & $41(52.6)$ \\
\hline Participated in KMC, $N(\%)$ & $9(26.5)$ & $67(85.9)^{\mathrm{a}}$ \\
\hline Age at KMC, mean ( \pm SD) & $18.0 \pm 2.7$ & $5.6 \pm 1.2^{\mathrm{a}}$ \\
\hline SNAPPE II Acuity Score ( \pm SD) & $5.20 \pm 1.0$ & $5.07 \pm 1.1$ \\
\hline Mortality, $N(\%)$ & $2(5.8)$ & $4(5.1)$ \\
\hline Growth velocity, g ( \pm SD) & $8.5 \pm 1.23$ & $13.2 \pm 0.83^{\mathrm{a}}$ \\
\hline Chronic lung disease, $N(\%)$ & $9(26.5)$ & $16(20.5)$ \\
\hline Necrotizing enterocolitis, $N(\%)$ & $1(2.9)$ & $2(2.5)$ \\
\hline LOS in days $( \pm$ SD) & $51.6 \pm 3.8$ & $46.4 \pm 5.8$ \\
\hline
\end{tabular}

Abbreviations: KMC, kangaroo mother care; LOS, length of hospital stay; SD, standard deviation.

${ }^{\mathrm{a}} \mathrm{Groups}$ whose values reached statistical significance using Student $t$-test where $p<0.05$ is considered significant. 
with confidence and competency in all levels of KMC transfer and especially for intubated infants or those receiving respiratory support. By improving nurses' comfort and competency with KMC, the training program also significantly enhanced nurses' perceived value of KMC. The utilization of a preeducation survey provided valuable objective data for the nurses to identify that their level of comfort and competency in KMC care provided them with a forum to understand that colleagues also had similar needs and allowed them to work collaboratively in gaining competency in the educational workshops. The instructional strategies used in both the didactic and practicum components of the KMC workshops were highly influential in determining critical thinking and clinical decision-making ability as well as in developing the psychomotor skill performances of the nurses. Hands-on simulation training and debriefings after each scenario helped the nurses to overcome many of their limitations and improved their confidence and skills in providing KMC, especially for infants receiving ventilator or respiratory support. KMC training also impacted on nurses' perception of the value of KMC. The impact of simulation training on confidence and subsequent wider use of KMC is in keeping with known benefits of simulation training. ${ }^{16}$ Although only 78 infants were included in this study after training, the number of infants and parents who benefited from KMC improved substantially after the nurse training period, suggesting that improved nurse KMC education, competency, and comfort led to and promoted KMC use among parents. The results of this study also indicate that perceived barriers to KMC utilization are impacted by competency levels that can be decreased through education that includes parent education role play, competency training, and continued supportive evaluation within the context of a balanced simulation-based program. Furthermore, this education translates to enhanced parent education and KMC utilization for eligible infants. Similar to other skills expected of nurses in the NICU, training in the utilization of KMC may be best approached by a standardized comprehensive KMC training workshop aimed at competency training linked with ongoing support to improve nurses' comfort in the KMC provision to decrease barriers to KMC use in the NICU.

\section{Acknowledgments}

This work was partly supported by the National Institutes of Health, Eunice Kennedy Shriver National Institute of Child Health \& Human Development, grant number 1R21HD059047 (K.D.H.M.) and an educational research grant to K.D.H.M. from the Jack Cary Eichenbaum Foundation. We are grateful to the neonatal nurses who participated in this study and Dr. Truc Hoang as well as medical director Dr. Yang Kim, Roselle Vittorino, and Adheip Mally for their assistance in partial data collection.
Conflict of Interest

The authors have no conflict of interest to declare.

\section{References}

1 World Health Organization. WHO. Kangaroo Mother Care. A practical guide. GenevaWorld Health Organization2003; Available at: http://www.who.int/maternal_child_adolescent/documents/ 9241590351/en/

2 Feldman R, Eidelman AI. Skin-to-skin contact (Kangaroo Care) accelerates autonomic and neurobehavioural maturation in preterm infants. Dev Med Child Neurol 2003;45(4):274-281

3 Conde-Agudelo A, Belizán JM, Diaz-Rossello J. Kangaroo mother care to reduce morbidity and mortality in low birthweight infants. Cochrane Database Syst Rev 2011;3(3):CD002771

4 Ludington-Hoe SM, Hosseini R, Torowicz DL. Skin-to-skin contact (Kangaroo Care) analgesia for preterm infant heel stick. AACN Clin Issues 2005;16(3):373-387

5 Nyqvist KH, Anderson GC, Bergman N, et al. Towards universal Kangaroo Mother Care: recommendations and report from the First European conference and Seventh International Workshop on Kangaroo Mother Care. Acta Paediatr 2010;99(6):820-826

6 Lawn JE, Mwansa-Kambafwile J, Horta BL, Barros FC, Cousens S. 'Kangaroo mother care' to prevent neonatal deaths due to preterm birth complications. Int J Epidemiol 2010;39(Suppl 1): i144-i154

7 Tessier R, Cristo MB, Velez S. Kangaroo mother care: a method for protecting high-risk low-birth-weight and premature infants against developmental delay. Infant Behav Dev 2003;26:384-397

8 Als H, McAnulty GB. The Newborn Individualized Developmental Care and Assessment Program (NIDCAP) with Kangaroo Mother Care (KMC): Comprehensive care for preterm infants. Curr Womens Health Rev 2011;7:288-301

9 Blomqvist YT, Rubertsson C, Kylberg E, Jöreskog K, Nyqvist KH. Kangaroo Mother Care helps fathers of preterm infants gain confidence in the paternal role. J Adv Nurs 2012;68(9):1988-1996

10 Tessier R, Charpak N, Giron M, Cristo M, de Calume ZF, Ruiz-Peláez JG. Kangaroo Mother Care, home environment and father involvement in the first year of life: a randomized controlled study. Acta Paediatr 2009;98(9):1444-1450

11 Blomqvist YT, Frölund L, Rubertsson C, Nyqvist KH. Provision of Kangaroo Mother Care: supportive factors and barriers perceived by parents. Scand J Caring Sci 2013;27(2):345-353

12 Hendricks-Muñoz KD, Louie M, Li Y, Chhun N, Prendergast CC, Ankola P. Factors that influence neonatal nursing perceptions of family-centered care and developmental care practices. Am J Perinatol 2010;27(3):193-200

13 Hendricks-Muñoz KD, Prendergast CC. Barriers to provision of developmental care in the NICU: neonatal nursing perceptions. Am J Perinatol 2007;24:71-78

14 Hendricks-Muñoz KD, Li Y, Kim YS, Prendergast CC, Mayers R, Louie M. Maternal and neonatal nurse perceived value of kangaroo mother care and maternal care partnership in the neonatal intensive care unit. Am J Perinatol 2013;30(10):875-880

15 Skene C, Franck L, Curtis P, Gerrish K. Parental involvement in neonatal comfort care. J Obstet Gynecol Neonatal Nurs 2012;41(6): 786-797

16 Jeffries PR. A framework for designing, implementing, and evaluating simulations used as teaching strategies in nursing. Nurs Educ Perspect 2005;26(2):96-103 